\title{
Developing Helical Grooved Drill Pipe for Increased Drive and Mud Pump Efficiency
}

\author{
Tushar Pahwa ${ }^{1 *}$ \\ ${ }^{1}$ Graphic Era University, Dehradun, India \\ *Corresponding author: Tushar Pahwa: pahwatushar@yahoo.com
}

\section{OPEN ACCESS}

Citation: Pahwa T. (2018)

Developing Helical Grooved Drill Pipe for Increased Drive and Mud Pump Efficiency.Open Science Journal 3(4)

Received: $29^{\text {th }}$ May 2018

Accepted: $13^{\text {th }}$ August 2018

Published: $8^{\text {th }}$ October 2018

Copyright:@ 2018 This is an open access article under the terms of the Creative Commons Attribution License, which permits unrestricted use, distribution, and reproduction in any medium, provided the original author and source are credited.

Funding: The author(s) received no specific funding for this work

Competing Interests: The author have declared that no competing interests exists.

\section{Abstract:}

Grooved drilled pipe is a type of drill pipe design, which can be a solution to some of major problems faced by drilling industry and increase overall efficiency of drilling as well. The problem in reference is differential drill pipe sticking. Simply put, grooved pipe is a type of drill pipe with spiral grooves on outer side (as used for experiments and calculations in this paper). This paper gives a comparative analysis between conventional and grooved drill pipes. Analysis is made on basis of theoretical formulas and working model using control scenarios to prove efficiency of grooved pipe over conventional drill pipe. Physical scale model was carefully fabricated to simulate conditions of a wellbore (in the best possible way for a scale model), carefully considering all the aspects of a conventional well. Theoretical formulas are also used to further support advantages of grooved pipe. Fabrication of model and experiment performed is meticulously explained in the paper. Almost everything comes with its own set of advantages and disadvantages. I have also listed a number of possible shortcomings of this idea. Even though results of experiment were better than anticipated andefficiency of grooved pipe over conventional pipe is quite significant, even for a scale model, the practicality of this project depends on whether advantages will outweigh disadvantages or not, in a real scenario. Further this paper aims to have an idea about future development studies and upcoming possibilities.

Keywords: Drill pipe sticking, Differential pipe sticking, Drive efficiency, Mud pump efficiency, Drill pipe design. 


\section{Introduction}

Drill pipe sticking occurs in $15 \%$ of the wells, and because of the delays involved and as well as the possibility of losing the drillstring, pipe sticking can dramatically increase drilling costs (Hossain, 2018). A pipe is considered stuck if cannot be freed from the hole without damaging the pipe and without exceeding rig's maximum allowed hook load (Schlumberger, 1991). Oil and gas industry spend $\$ 200$ to $\$ 500$ million each year in order to tackle stuck pipe incidents (Hossain, 2018). In order to have better and successful drilling operations, the elimination and mitigation of risks and drilling problems is necessary.

This paper is based on an idea of using spirally grooved drilled pipe for drilling operations instead of conventional drill pipe. This project aims at reducing above numbers while increasing mud pump and drive efficiency. Analysing and comparing both pipes has given a number of significant advantages that grooved pipe has over conventional drill pipe. These advantages are proved theoretically as well as using physical scale models. Additional modifications are also listed, which could be experimented with, in future and can possibly boost these advantages.

Practically, there could be many type of grooves like variation in depth, angle, gap, width, pitch and inner/outer, and there could be a perfect combination of these which would be most efficient overall or for a particular scenario.

To understand something completely one must know what it provides in terms of advantages, but also disadvantages. All the possible disadvantages of grooved pipe over a conventional pipe that could be contemplated have been listed in this paper, so that they can be worked upon and minimized to whatever extent possible.

The practicality of this project depends on whether advantages will outweigh disadvantages or not, in a real scenario.

This type of drill pipe could be best suited for drilling in conditions where differential pipe sticking could occur (like unconsolidated formations, somewhere thick mud cakes are expected to form or geopressure formations), or for situations where high drag forces act upon drill pipe (directional or horizontal drilling).

\section{Theoretical Review}

\section{Advantages}

- Mud up-thrust in annulus: the grooves in the drill pipe are helically wound in the direction of rotation. These grooves will help provide an additional upthrust to the mud travelling towards surface in annular space of the well.

- Increased mud pump efficiency: because of additional force, pushing mud against gravity, mud pumps can be said to be little more efficient.

- Lower torque required by drive mechanism to rotate drill pipe:As direction of helical movement of grooves is same as direction of movement of mud,in a system where mud is travelling up the 
annulus, and two drill pipes are rotating mutually independently under same conditions with one difference, one drill pipe is helically grooved while other is not, the grooved pipe will rotate more freely than normal pipe.

- Grooves also reduce chances of pipe sticking and decrease force required to unstick a differentially stuck pipe which is later proved theoretically.

\section{Disadvantages}

- Compromised compressive strength of pipe in case of inward shaved grooves. Inward grooves can be formed by shaving off outer surface of drill pipe which can decrease its net thickness and hence strength.

- Additional cost of grooving and/or chrome polishing.

- Rock cuttings jamming grooves (which can be avoided by using well rounded grooves instead of angled grooves).

- Additional hook load in case of outward welded grooves. Outward welded grooves are metal strips that are welded on outer surface of drill pipe to form outward protruding helical grooves. These additional weights of welded metal will account to a significant increase in net hook load when computed for a large number of drill pipes.

\section{Additional design points for practical purposes}

- Types of grooves can be single or double helical.

- Pipe with grooves on outer side were used in this paper. Similar results could be expected from grooves on inner side of the pipe, or even better from a combination of both.

- Polishing of grooves can reduce coefficient of friction, which is increased by extra surface area. Reducing coefficient of friction of grooves can further reduce force required to unstick a differentially stuck pipe, which is explained in detail further in this paper.

- Experimenting with varying pitch, thickness, angle and depth of groove to obtain most efficient orientation.

- Use of a stronger material than usually used would be advisable; to compensate for compromised compressive strength.

\section{Proofs}

\section{Differential Pipe Sticking}

Differential sticking occurs in permeable zone when drill collars, drillpipe, or casing get embedded in mud cake and pinned to the borehole wall by difference between mud's hydrostatic pressure and a lower formation pressure. 

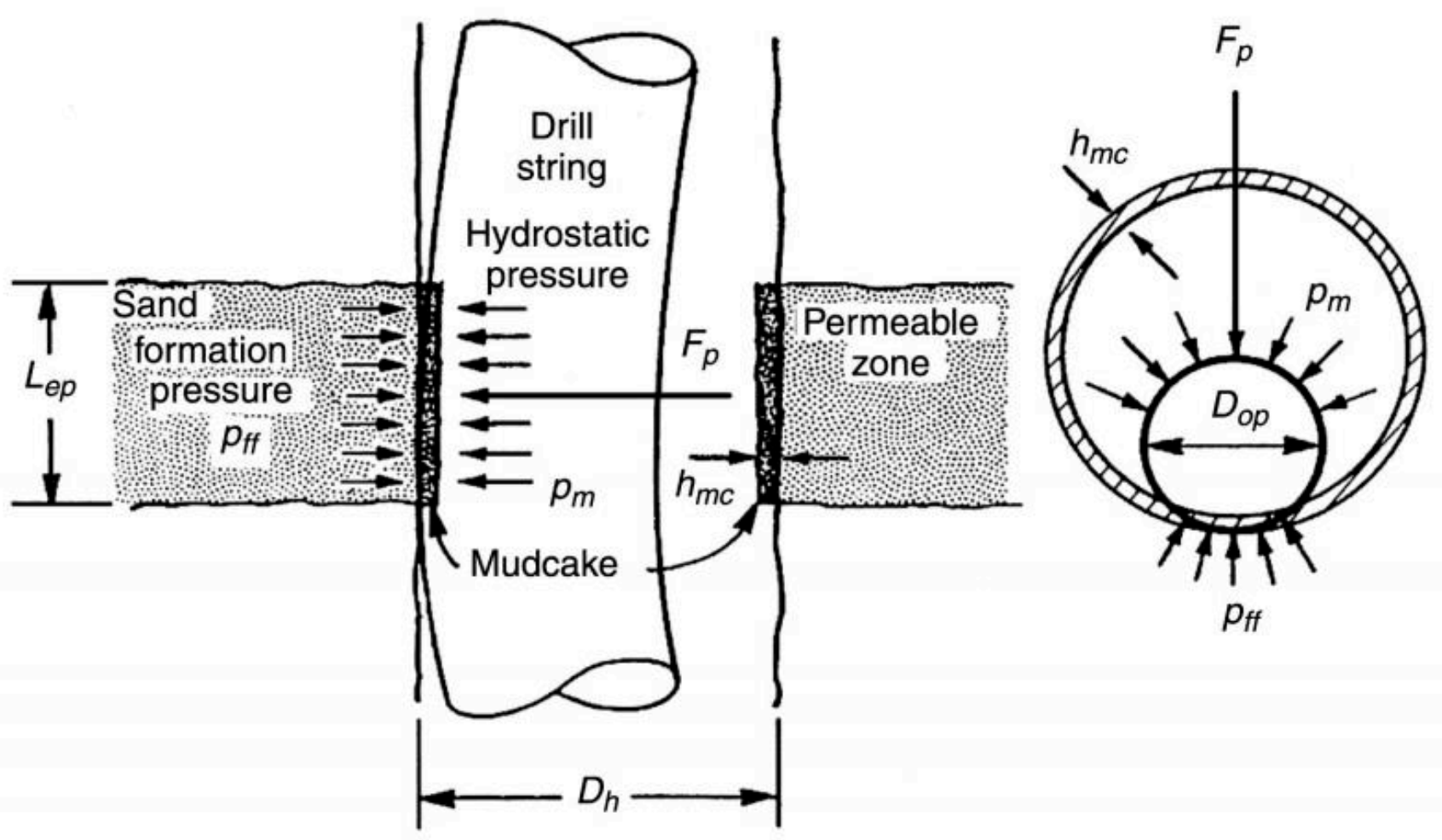

Figure 1 Differential Pipe Sticking

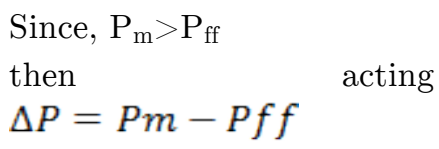

where,

$\mathrm{P}_{\mathrm{m}}=$ Mud pressure

$\mathrm{P}_{\mathrm{ff}}=$ Formation pressure.

The force, $F_{p}$ required to unstick pipe is a function of differential pressure, coefficient of friction $(f)$ and contact area $\left(\mathrm{A}_{\mathrm{c}}\right)$,

$F p=f \cdot \Delta P \cdot A c$

and

$$
A c=2 \operatorname{Lep}\left\{\left(\frac{D h}{2}-H m c\right)^{2}-\left[\frac{D h}{2}-\frac{H m c(D h-H m c)}{D h-D o p}\right]^{2}\right\}^{0.5}
$$

where,

Lep $=$ length of permeable zone

$\mathrm{Dh}=$ hole diameter

Hmc $=$ mudcake thickness

$\mathrm{Dop}=$ pipe outer diameter. 
Assuming grooves are right angle grooves, with outer diameter of pipe at groove $=$ Dog

Then force, $\mathrm{F}_{\mathrm{gp}}$ required to unstick grooved pipe

$F g p=\Delta P \cdot f(\mathrm{Acp}+\mathrm{Acg})$

Since, $A c=A c p+A c g$

$\mathrm{A}_{\mathrm{cp}}=$ area of contact of outer pipe with formation

$\mathrm{A}_{\mathrm{cg}}=$ area of contact of groove with formation.

If (Dop- Dog) $>$ Hmc, then Acg will almost be equal to zero thus, $F g p=\Delta P . f$. Acp

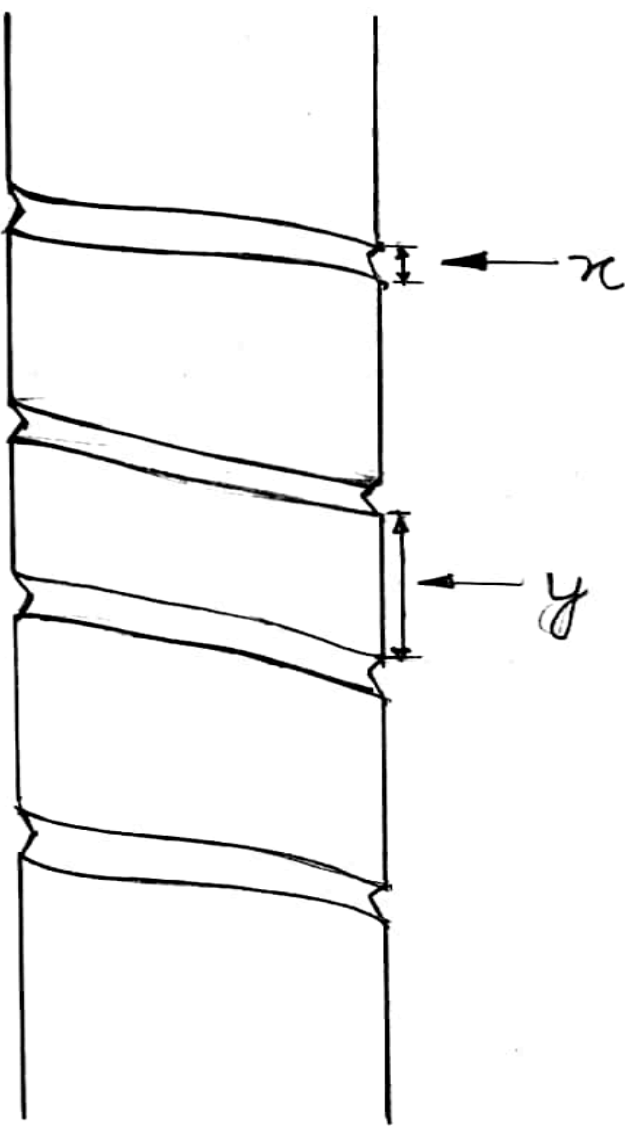

Figure 2 Grooved pipe

Since Ac is directly proportional to the length of permeable zone in contact with drill pipe, it is safe to say that,

$A c p=\frac{y}{y+x} A c$

$\frac{y}{y+x}<1$

we can definitely say that $\mathrm{Acp}<$ Ac.

Comparing values of force required to unstick a, regular pipe $(F p=f . \Delta P . A c$, eqn. 2) and a grooved pipe $(F g p=\Delta P . f$. Acp, eqn 5$)$, it can be seen that Fp $>$ Fgp. Hence it is easier to unstick a grooved drill pipe than a normal drill pipe. 


\section{Mud up thrust and torque reduction}

To prove that grooved drill pipe will provide an additional mud up-thrust in annulus and reduce minimum torque required to rotate pipe, a model is prepared, in which a hollow cylindrical container filled with a dense fluid (to act as drilling mud) will act as a borehole. 3 hollow metal pipes are taken, two grooved for experimental purpose and third normal for control purpose. These 3 pipes are rotated separately with help of a DC motor (with high torque and low Rotations per Minute (RPM)) while keeping all the conditions same. Same and constant pressure is applied from top of the pipes to keep the fluid flowing from top to bottom inside the pipe, and from bottom to top, outside the pipe (annulus); this is done to simulate mud flow inside drill pipe and annulus.

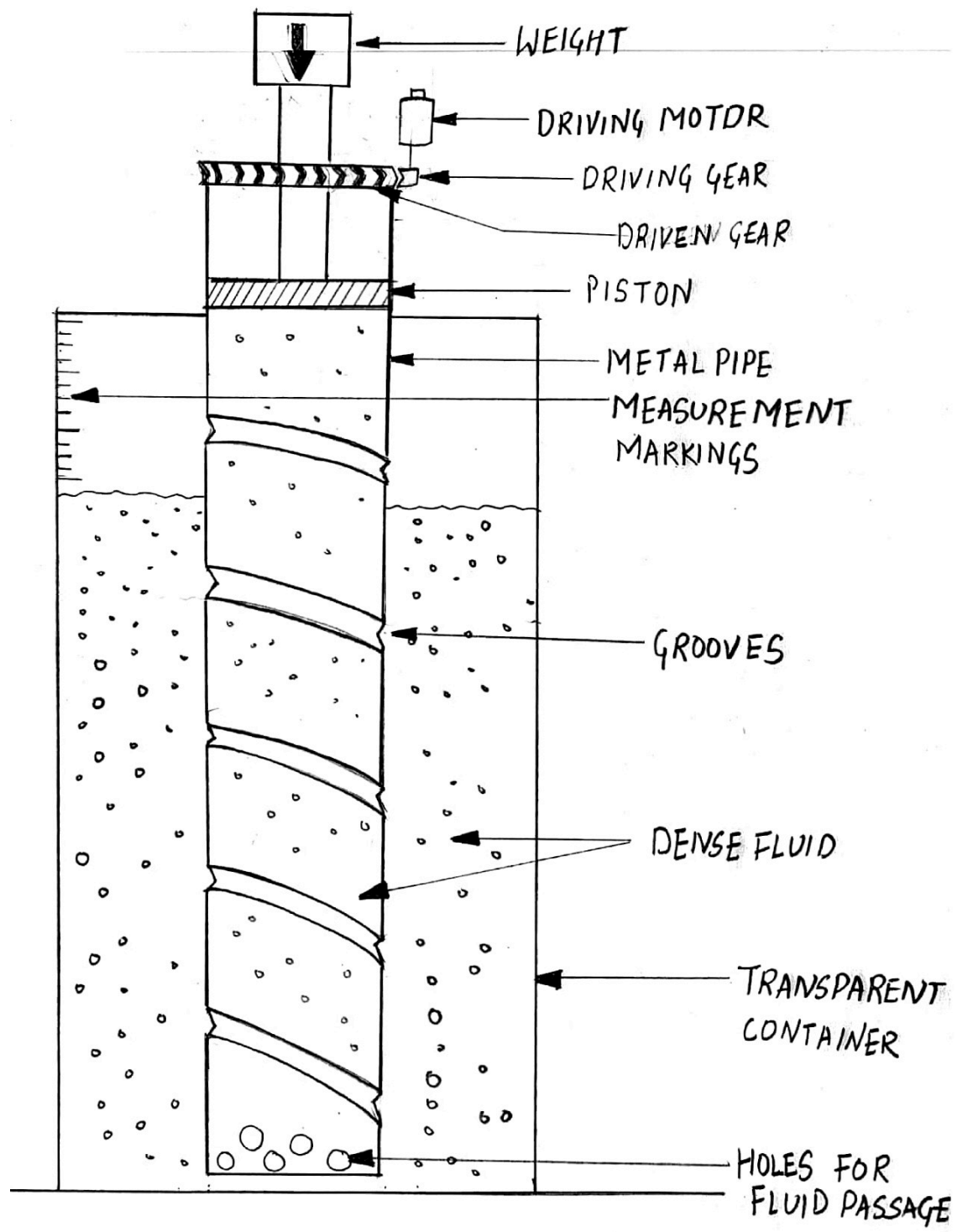

Figure 3 Schematic of working model 
These pipes are rotated with a constant pressure on them. Time taken by each pipe to bring fluid to the top of the outer pipe is noted and number of rotations of drill pipes is also noted to calculate RPM of both systems. If fluid level in grooved pipe container rises faster than fluid level in normal pipe, it will confirm that grooved pipes provide an additional mud up-thrust. Since torque is inversely proportional to RPM (torque $=\{$ horsepower*5252 $\} / \mathrm{RPM}$ ) if higher RPM is observed in grooved pipe than normal pipe (horsepower is constant in every case), it will confirm that grooved pipe requires lesser torque to rotate than normal pipe.

\section{Fabrication of Working Model}

This model shows difference in efficiency of a conventional pipe and grooved pipe under same physical conditions. Three identical hollow steel pipes of OD (Outer Diameter) $4.8 \mathrm{~cm}$, thickness $0.9 \mathrm{~cm}$ and length $20.5 \mathrm{~cm}$ are taken. These three pipes would act as drill pipes. Two of these are helically grooved with varying gap and third is to be used as control. Grooves are made of thickness $4 \mathrm{~mm}$, on lathe machine.

Ratio of groove thickness to pipe thickness is kept high, (compromising strength of pipe) to obtain an easily observable and distinguishable result, all this while recognising limitations in terms of length of pipe and strength of motor of a scale model.

At the bottom of these pipes, 4 holes of $2 \mathrm{~mm}$ diameter are drilled to enable mud circulation in annulus.

Another steel pipe of OD $9 \mathrm{~cm}$ and thickness $0.8 \mathrm{~cm}$ is taken, which will act as casing in this model. These geometrical charactristics were calculated keeping in mind actual ratio of average diameters of drill pipe to casing.

This outer pipe is gas welded onto to steel board to provide stability to the system. Gears are fixed on top end of inner steel pipes in order to rotate them using a DC powered motor. Worm type gear is installed to transfer rotary motion from motor to pipe. A rotary bearing system is installed on bottom and sides of inner pipes to ensure centralization of pipe and friction less rotation.

A piston system is installed inside inner pipe to act as mud pump by exerting fixed weight onto the mud, which will be pushed out of holes at the bottom, into the annulus. Motor is mounted on outside of outer pipe to act as drive system and rotate inner pipe. Whole system is made leakproof by careful welding, to prevent leakage of fluid and deviation in values to be observed. The system is designed in such a way that inner pipes can be interchanged for different experiment and control tests. 


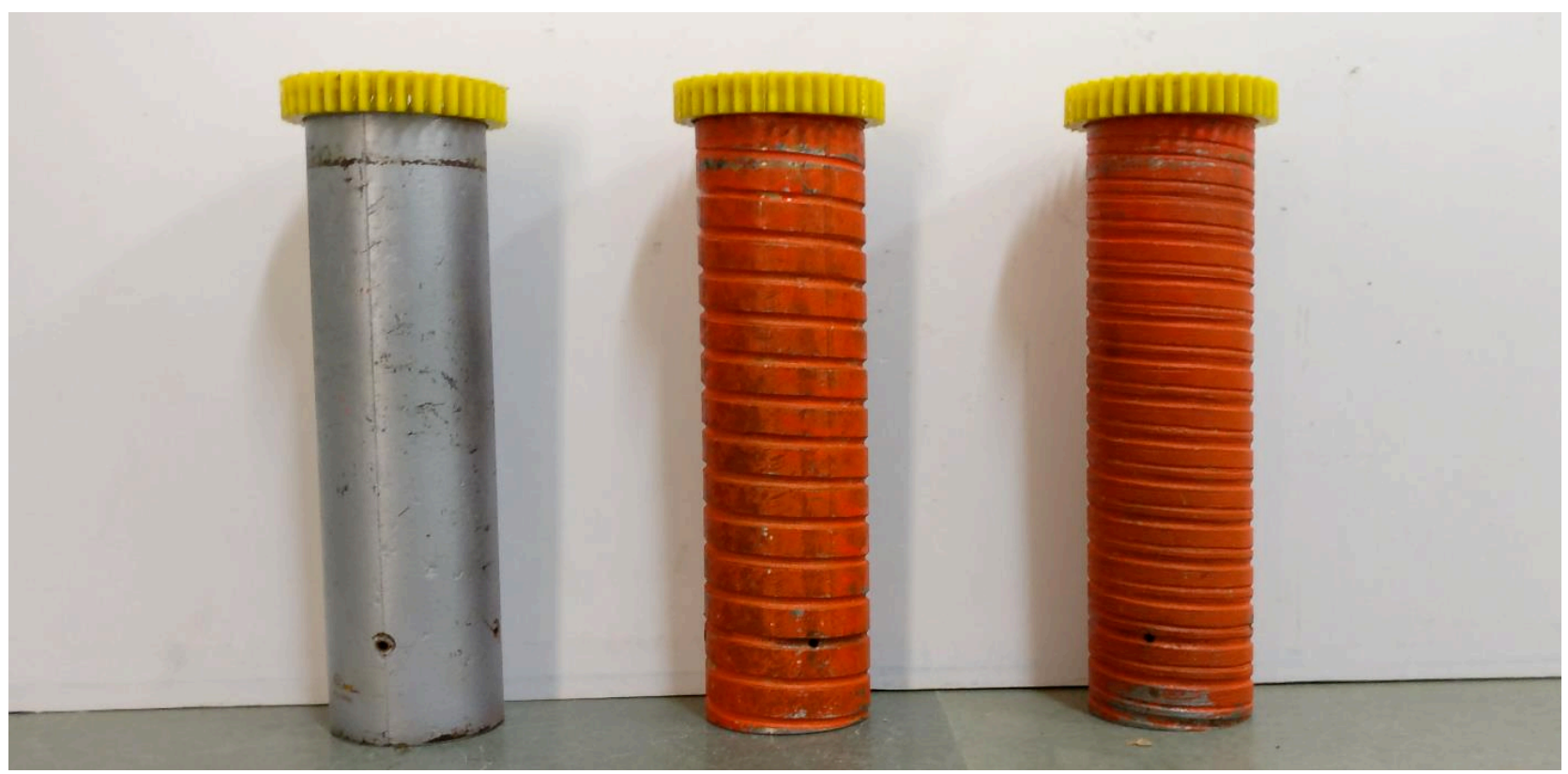

Figure 4 Control Pipe, Single Groove Pipe, \& Double Grooved Pipe

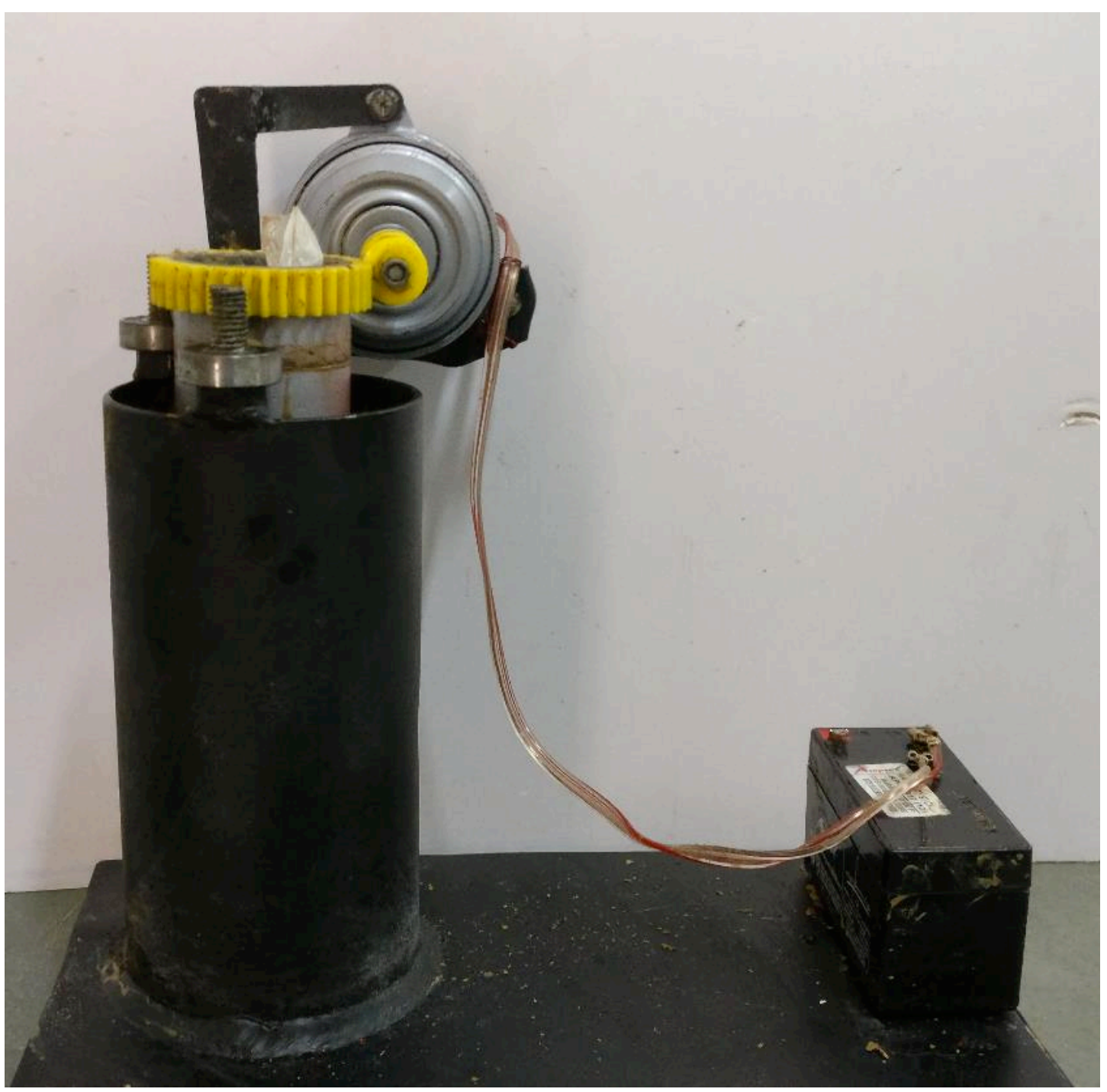

Figure 5 Working Model (front view) 


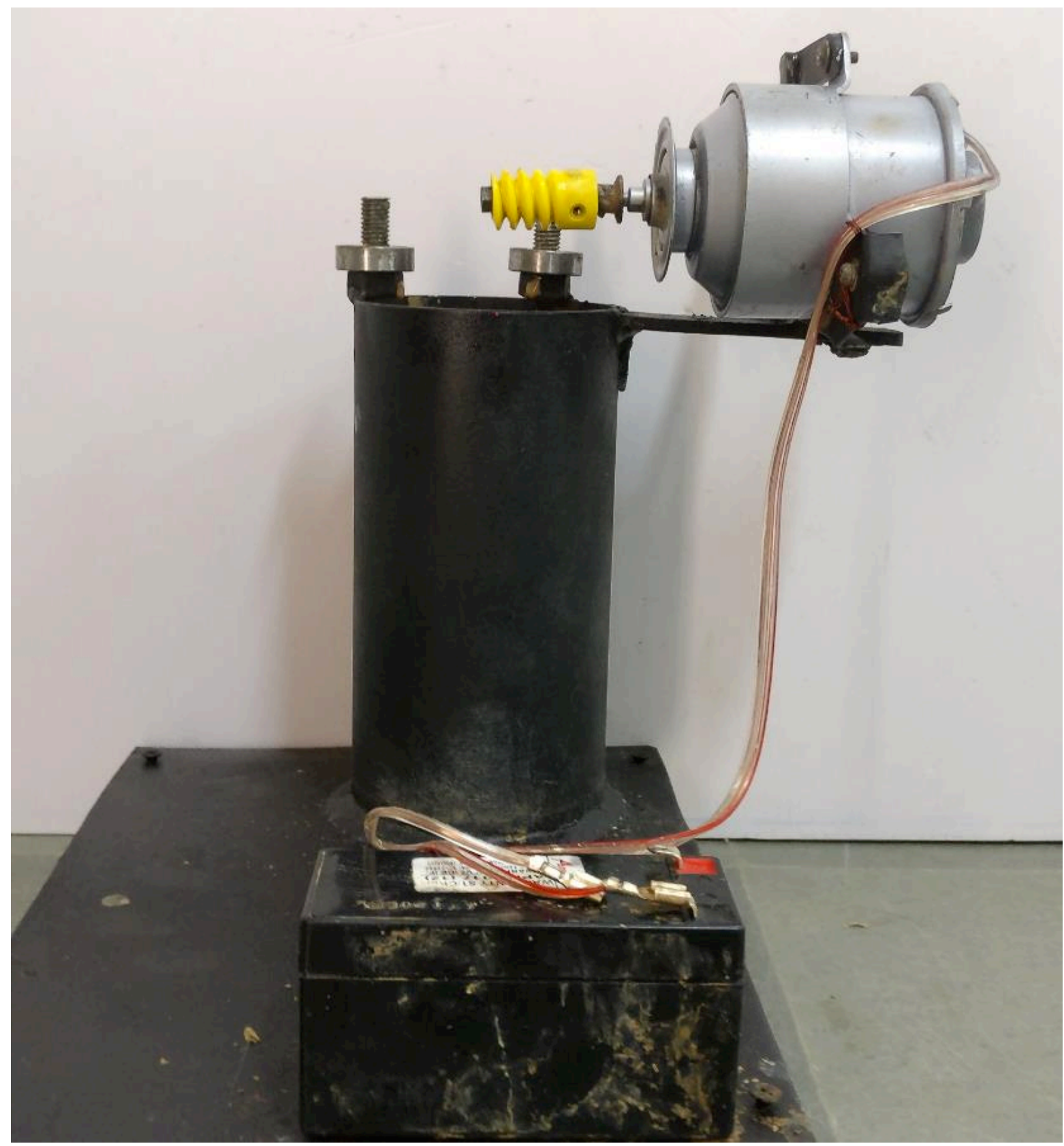

Figure 6 Working Model (side view)

\section{Experiment and Result}

\section{Experiment}

First, drilling mud was prepared using $600 \mathrm{ml}$ water, $75 \mathrm{~g}$ bentonite, $22 \mathrm{~g}$ barite and $3 \mathrm{~g}$ starch. The mud was mixed using a mechanical stirrer. Density of resultant mud was found to be 9.05ppg. This mud was used in all the experiments. Weight of $245 \mathrm{~g}$ is kept on the piston above (mud pump), so as to 
exert pressure on mud and push it out of the pipe, into the annulus. Pipe is fitted inside the casing, and mud is filled till the top of the inner pipe and allowed to settle for 10-15 secs, then piston (with weight) is inserted in the pipe and motor is started. Total time for piston to reach bottom dead point from top dead point is noted for each individual pipe. 3 readings are taken per pipe. For every new reading, mud is completely removed from the system and filled again from the top. Control pipe is the conventional drill pipe. RPM of each pipe is also noted.

\section{Result}

Time Comparison

\begin{tabular}{l|l|l|l}
\hline S.no & Control Pipe (secs) & Single Groove Pipe (secs) & Double Groove Pipe (secs) \\
\hline 1. & 16.77 & 12.81 & 11.65 \\
\hline 2. & 16.45 & 12.97 & 11.62 \\
\hline 3. & 16.83 & 12.77 & 11.74 \\
\hline Mean & 16.68 & 12.85 & 11.67 \\
\hline
\end{tabular}

RPM Comparison

\begin{tabular}{l|l}
\hline Pipe & RPM \\
\hline Control & 58 \\
\hline Single Groove & 59 \\
\hline Double Groove & 59 \\
\hline
\end{tabular}

\section{Result Analysis}

Results show significant decrease in time taken by grooved pipe to bring mud to the top than conventional pipe. This decrease in time is even greater for double grooved pipe, hence showing positive impact of using this type of drill pipe. Approximate 4 seconds of time saving is observed for $15 \mathrm{~cm}$ of drill pipe, so for thousands of feet of drill pipe, time and energy saving would be considerably high.

Higher RPM of grooved pipe and double grooved pipe than control pipe show that using grooved pipe is more efficient for drive system. 

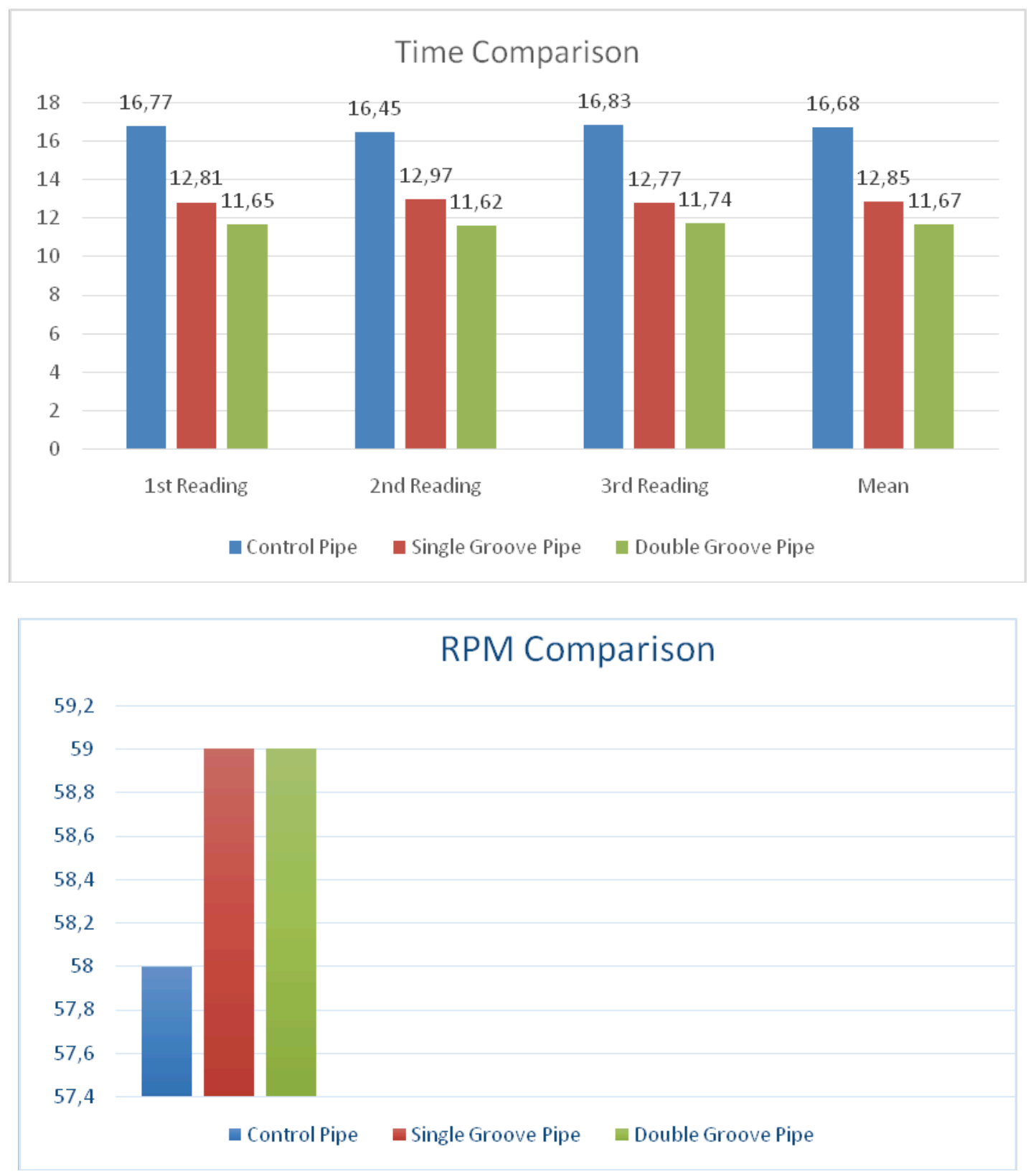

\section{Conclusion}

The results of this report confirm advantages of grooved pipe over conventional pipe. Experimental results show a difference of 3.83 seconds per $15 \mathrm{~cm}$ for single groove pipe and 5.01 seconds per $15 \mathrm{~cm}$ for double grooved pipe. This decrease in time proves that grooved pipe requires less torque for rotation and provides extra mud up-thrust in the annulus. The time difference would increase as length of pipe is increased, so for a full-scale model, where drill pipe is thousands of feet long, grooved pipes can be of a very significant effect. Higher RPM of grooved pipe show that for same torque grooved pipe rotates more efficiently hence faster than control pipe. Therefore, to achieve same value of RPM, grooved drill pipe would require less torque than conventional drill pipe. 
Theoretical formulas above prove that grooved pipe is easier to unstick in case of differential pipe sticking, when compared with conventional pipe. Thus, outcomes of this report look momentous and promising for future, and opens doors for more experiments, which could be experimenting with different types of grooves (length, depth, pitch etc.) and studying effects on directional and horizontal drilling.

\section{References:}

Bourgoyne, A.T., Millheim, K.K., Chenevert , M.E. et al. 1986. Applied Drilling Engineering. Richardson, Texas: Textbook Series, SPE.

Hossain M.E., Islam M.R. 2018. Drilling Engineering Problems and Solutions: A Field Guide for Engineers and Students.

Schlumberger Oilfield Review 1991. Causes, Detection and Prevention. 